\title{
The 1-way on-line coupled atmospheric chemistry model system MECO(n) - Part 3: Meteorological evaluation of the on-line coupled system
}

\author{
C. Hofmann ${ }^{1,2}$, A. Kerkweg ${ }^{2}$, H. Wernli ${ }^{3}$, and P. Jöckel ${ }^{4}$ \\ ${ }^{1}$ Meteorologisches Institut der Universität Bonn, 53121 Bonn, Germany \\ ${ }^{2}$ Institut für Physik der Atmosphäre, Johannes-Gutenberg Universität Mainz, 55128 Mainz, Germany \\ ${ }^{3}$ Institute for Atmospheric and Climate Science, ETH Zurich, 8092 Zurich, Switzerland \\ ${ }^{4}$ Deutsches Zentrum für Luft-und Raumfahrt (DLR), Institut für Physik der Atmosphäre, 82234 Oberpfaffenhofen, Germany
}

Correspondence to: C. Hofmann (hofmach@uni-mainz.de)

Received: 6 June 2011 - Published in Geosci. Model Dev. Discuss.: 18 July 2011

Revised: 30 September 2011 - Accepted: 26 October 2011 - Published: 19 January 2012

\begin{abstract}
Three detailed meteorological case studies are conducted with the global and regional atmospheric chemistry model system ECHAM5/MESSy $(\rightarrow \text { COSMO/MESSy })^{n}$, shortly named $\operatorname{MECO}(\mathrm{n})$. The aim of this article is to assess the general performance of the on-line coupling of the regional model COSMO to the global model ECHAM5. The cases are characterised by intense weather systems in Central Europe: a cold front passage in March 2010, a convective frontal event in July 2007, and the high impact winter storm "Kyrill" in January 2007. Simulations are performed with the new on-line-coupled model system and compared to classical, off-line COSMO hindcast simulations driven by ECMWF analyses. Precipitation observations from rain gauges and ECMWF analysis fields are used as reference, and both qualitative and quantitative measures are used to characterise the quality of the various simulations. It is shown that, not surprisingly, simulations with a shorter lead time generally produce more accurate simulations. Irrespective of lead time, the accuracy of the on-line and off-line COSMO simulations are comparable for the three cases. This result indicates that the new global and regional model system MECO(n) is able to simulate key mid-latitude weather systems, including cyclones, fronts, and convective precipitation, as accurately as present-day state-of-the-art regional weather prediction models in standard off-line configuration. Therefore, MECO(n) will be applied to simulate atmospheric chemistry exploring the model's full capabilities during meteorologically challenging conditions.
\end{abstract}

\section{Introduction}

This third part of a series of articles about the newly developed 1-way on-line coupled global and regional chemistry model system $\mathrm{MECO}(\mathrm{n})$ is dedicated to its meteorological evaluation. Kerkweg and Jöckel (2012a) describe the connection of the Modular Earth Submodel System (MESSy, Jöckel et al., 2005, 2010) to the limited-area weather prediction and climate model of the COnsortium for Small-scale MOdeling (COSMO, Doms and Schättler, 1999; COSMOCLM, Rockel et al., 2008) resulting in the limited-area atmospheric chemistry model COSMO/MESSy. Alternative approaches in on-line coupling of regional chemistry models operate with constant boundary conditions for chemical tracers (e.g. WRF/Chem, Grell et al., 2005) or use boundary data, calculated using different chemistry implementations (i.e. different chemical species and reactions, e.g. COSMOART, Knote et al., 2011). The presented system MECO(n) profits from key characteristics of the previously established global model ECHAM5/MESSy for Atmospheric Chemistry (EMAC, Jöckel et al., 2006), in particular from the fact that most chemistry related processes have been formulated scale independently and are thus directly applicable to smaller scales. Secondly, as EMAC and COSMO/MESSy can use the same chemistry implementations, the lateral boundary conditions for the chemical tracers are consistent.

Usually boundary data for limited-area weather prediction and climate models are calculated off-line every few hours, at the times when output from the coarser driving model is available, and stored on disk. For the COSMO model, this is typically performed with the INT2LM tool provided by the German Weather Service (DWD, Deutscher 
Wetterdienst). As it is intended to use COSMO/MESSy for detailed chemistry applications, a hundred or more additional boundary fields (e.g. for each chemical tracer) would need to be processed and stored. To limit the additional workload, the storage demands, and to potentially increase the accuracy of the treatment of the boundary conditions, COSMO/MESSy has been further developed to be driven on-line by the global EMAC model or a coarser COSMO/MESSy model (Kerkweg and Jöckel, 2012b). Technically this includes the implementation of the pre-processing tool INT2LM into COSMO/MESSy which is explained in detail in Kerkweg and Jöckel (2012b). This online version of INT2LM is called INT2COSMO. In this way, a system for the concurrent execution of one EMAC and an arbitrary number of COSMO/MESSy model instances within the same MPI (message passing interface) environment has been developed. Each COSMO/MESSy model instance is driven by another, coarser COSMO/MESSy instance or by ECHAM5/MESSy.

The implementation is such that several nesting instances can be applied in one simulation. This means for instance, it is possible to perform simultaneous simulations in different regions at the same time, to simulate ensembles in the same region, to work with interlaced nests of one region with increasing resolution, or any combination of those.

The setup of the system and the data exchange are driven by the Multi-Model-Driver (MMD) library, which is part of the MESSy system. The reader is referred to Kerkweg and Jöckel (2012b) for the technical details of this coupling. The 1-way on-line coupled model system ECHAM5/MESSy $(\rightarrow \text { COSMO/MESSy })^{n}$ is named MECO(n) (MESSy-fied ECHAM and COSMO), where $\mathbf{n}$ denotes the number of nested COSMO/MESSy instances.

Before MECO(n) can be used for the first atmospheric chemistry applications, it is important to test its performance for purely meteorological simulations (i.e. without chemistry). Since potential applications of this model system are in the area of chemical weather prediction, air pollution studies, and the interpretation of chemical observations during field experiments, the question arises, how accurately the COSMO/MESSy model, on-line coupled to the global climate chemistry model EMAC, captures specific meteorological events, compared to the classical setup, where COSMO is driven off-line by meteorological data from a global model forecast or analyses.

To address this question, we investigate simulations of three meteorologically diverse cases:

1. a cold-frontal passage over Germany in March 2010,

2. an intense linearly organised convection event during the COPS campaign in July 2007, and

3. the development of the winterstorm "Kyrill" in January 2007.
The first case has been chosen to test the model's performance for a precipitation event induced by large-scale dynamical forcing. As events with deep convection are particularly challenging to predict accurately, the second case probes for this. In the third case study we investigate the performance of the model to capture the evolution of the winterstorm "Kyrill". For all cases, simulations are performed with the new model system and compared to the classical approach, where COSMO is driven off-line with boundary conditions provided from ECMWF analyses. Various measures are used to compare the quality of the two model setups (mean and root mean square (RMSE) values of selected variables in predefined regions; spatial structure and amplitude of precipitation; track and intensity of synoptic-scale weather system). This approach allows to investigate the model performance in some detail for specific meteorological situations - in contrast to a more statistical approach, which would be based upon a systematic evaluation of longterm parallel experiments with the classical approach and the new model system.

At first, differences between the COSMO model and $\operatorname{MECO}(\mathrm{n})$ are depicted in Sect. 2. Section 4 outlines the setup of the $\mathrm{MECO}(\mathrm{n})$ system, after the evaluation strategy has been explained in Sect. 3. The case studies are investigated in Sect. 5, while Sect. 6 informs about some additional findings in view of the coupling strategy. Finally, the results of the case studies are summarised and conclusions are drawn for the future application of the new model system.

\section{Differences between COSMO and $\operatorname{MECO}(n)$ : provision of boundary data}

Since the MECO(n) system shall be used in future to investigate, among others, chemistry aspects of distinct meteorological events, the general performance of $\mathrm{MECO}(\mathrm{n})$ in simulating specific meteorological situations has to be tested first. Performing simulations using $\mathrm{MECO}(\mathrm{n})$ without chemistry, the main difference compared to usual COSMO model simulations lies in the provision of boundary data. This is illustrated in Fig. 1.

Performing simulations using the classical COSMO model setup, the COSMO model is driven off-line by 6-hourly boundary data based on ECMWF analyses as shown in Fig. 1a. For the considered cases, ECMWF analysis data are available in T799L91 resolution. After interpolation and transformation using the pre-processing tool INT2LM (step 1 in Fig. 1a), the obtained initial and boundary fields have to be stored on disk, before they can be used to drive the off-line COSMO model simulation (step 2). For many changes in the COSMO model namelist setup for further simulations, e.g. a modification of the model domain or the vertical or horizontal resolution, step 1 in Fig. 1a has to be executed again. Simulations performed with this setup are hereafter called "off-line simulations". 

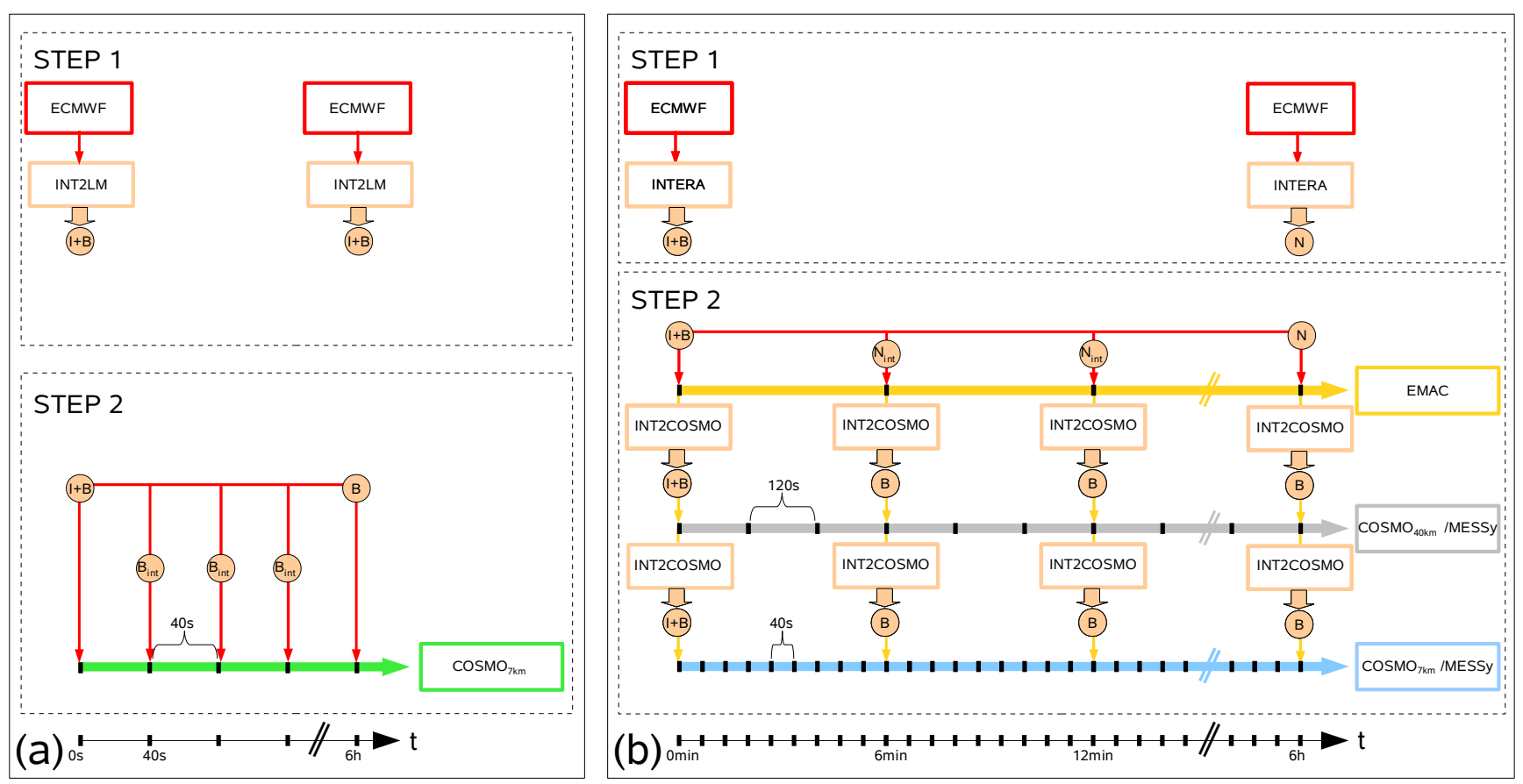

Fig. 1. Schematic illustration of the temporal evolution of (a) off-line and (b) on-line simulations. Abbreviations are used for boundary (B), initial (I), nudging (N) and interpolated (int) data.

The second simulation type uses the newly developed $\operatorname{MECO}(\mathrm{n})$ system and is hereafter called "on-line simulation". Figure $1 \mathrm{~b}$ schematically illustrates this system, which setup is described in detail in Sect. 4. For these simulations, boundary data are provided on-line at every driving model time step via INT2COSMO. Thus, on-line simulations get its boundary conditions more frequently than the off-line simulations, but they are very likely less accurate than the ones from analyses, which profit from the data assimilation cycle using direct observations. For simulating specific meteorological situations, it is necessary to nudge the climate model EMAC (step 1 in Fig. 1b). After interpolation using the pre-processing tool INTERA ${ }^{1}$ once, the fields can be stored and used again for further simulations, independent of the COSMO model namelist setup.

It is therefore an important and open question whether $\operatorname{MECO}(\mathrm{n})$, driven by the chemistry climate model EMAC, is able to reach a similar accuracy as a standard COSMO simulation in simulating meteorological events.

\section{Evaluation strategy and validation data}

The central point of this article is to show that the MECO(n) system can be used in the future to investigate air chemistry aspects of distinct meteorological events.

\footnotetext{
${ }^{1}$ http://wekuw.met.fu-berlin.de/ IngoKirchner/nudging/ nudging/software/index.html
}

Accordingly, the meteorological results of an on-line coupled COSMO/MESSy simulation must be comparable in terms of quality to usual COSMO model simulations. For our case studies, COSMO simulations are performed with a $7 \mathrm{~km}$ (1st and 2nd case) and a $14 \mathrm{~km}$ (3rd case) horizontal grid spacing, respectively. The coarser resolution for the $3 \mathrm{rd}$ case has been chosen because of the large model domain required to capture the life-cycle of the cyclone.

For easier reference, the simulations on the $7 \mathrm{~km}(14 \mathrm{~km})$ grid are simply called "COSMO simulations" and the respective model domain, as illustrated in Fig. 2, is called "COSMO region". To differentiate between simulations two indices are used:

- The first one, "off" or "on" indicates whether the simulation is an off- or on-line simulation, respectively. An additional index, "res" is only used in Sect. 6 and indicates a "restart simulation", where EMAC simulations are started prior to the nested COSMO simulations.

- The second label provides the time at which the COSMO simulation is started, including the day and the full hour in UTC.

For instance, $\mathrm{COSMO}_{\text {on,26_00 }}$ is an on-line COSMO simulation started at the 26th of the respective month at

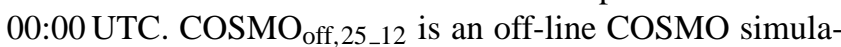
tion started $12 \mathrm{~h}$ earlier as $\mathrm{COSMO}_{\mathrm{on}, 26 \_00}$.

As described in Sect. 2, there are significant differences in providing boundary data between on- and off-line 


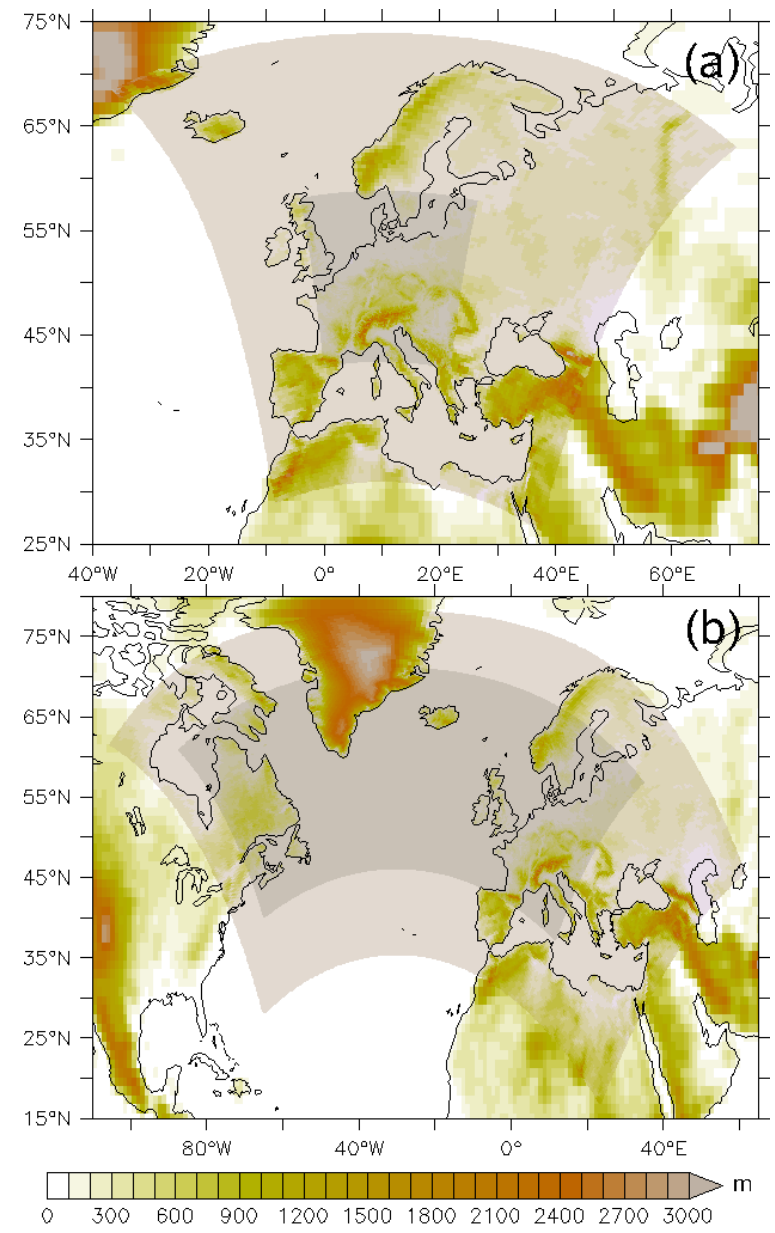

Fig. 2. Model setup, showing smaller and larger COSMO instances nested within EMAC. The height of the topography is shown (colours, in ma.s.l.) to illustrate the different resolutions of the instances of the $\operatorname{MECO}(2)$ system. Panel (a) shows the model setup used for the frontal passage over Germany (Sect. 5.1) and the convective processes during the COPS campaign (Sect. 5.2), panel (b) shows the setup for winterstorm "Kyrill" (Sect. 5.3).

simulations. For longer lead times before a specific meteorological precipitation event, the impact of boundary variations becomes more important than the physical parametrisation in the COSMO model (Gebhardt et al., 2011). Boundary data for $\operatorname{MECO}(\mathrm{n})$ is provided by EMAC, which is a chemistry climate model, i.e. per se not constructed to reproduce specific meteorological situations. Yet, this can be achieved by a weak Newtonian relaxation ("nudging") towards analysis or reanalyses data presenting the observed meteorology. The longer the lead time, the less influence has the initial condition for EMAC and the developing dynamic is only guided on the synoptical scale by the nudging procedure. Therefore, simulations with different lead times before the events are performed (Fig. 3). For all case studies, on-line simulations with a simultaneous start of all model instances (EMAC

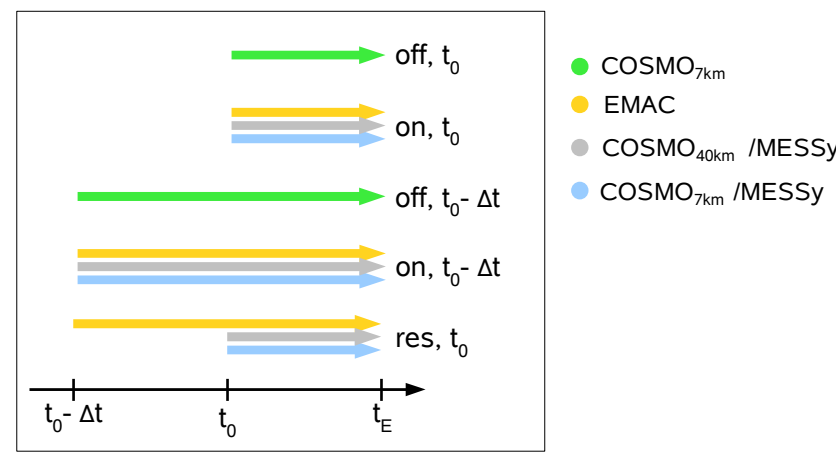

Fig. 3. Illustration of the different start times $t_{0}$ and $t_{0}-\Delta t$ of the on- and off-line simulations, compared in Sects. 5 and 6. The colours used for the different models correspond to Fig. 1.

and the two COSMO/MESSy instances) at time $t_{0}$ and at an earlier time, $t_{0}-\Delta t$ are performed. They are compared to the respective off-line simulations with corresponding start times. Additionally, for the first and second case study, "restart simulations" are performed, where EMAC simulations are started at time $t_{0}-\Delta t$, prior to the COSMO simulations started at time $t_{0}$ (Sect. 6). All simulations end at the same time $t_{E}$.

The off- and on-line simulations use the same COSMO model namelist setup, i.e. the same model grid and physical parametrisations. For the model evaluation we compare the respective on-line and off-line COSMO simulations to the ECMWF analyses interpolated from the spectral model resolution T799L91 to a regular grid with a horizontal resolution of $0.5^{\circ}$. The ECMWF analysis fields are used as reference (or "truth") except for the evaluation of the simulated precipitation field, for which, dependent on the case, two observational data sets have been available: for the first case study the simulated precipitation is compared to hourly observational data from about 1260 rain gauge stations in Germany, operated by the $\mathrm{DWD}^{2}$. Additionally, precipitation forecasts from the global ECMWF model are used for the comparison. A different precipitation data set is used for the evaluation of the second case study. Here, daily rain gauge measurements are interpolated to the COSMO domain with $7 \mathrm{~km}$ grid spacing using the gridding technique by Frei and Schär (1998). The resulting fields were then combined with hourly radar composites to obtain gridded fields of hourly precipitation in Germany, as described in Paulat et al. (2008). Not only the COSMO simulations, but also the driving models (ECMWF and EMAC) are compared with these data.

\footnotetext{
${ }^{2}$ http://cdc.dwd.de/catalogue/srv/de/main.home
} 


\section{Model setup}

For the on-line simulations EMAC in T106L31 resolution is used as the global driving model. As the difference in resolution between a spectral T106 model and the target 7-km COSMO grid is large, an intermediate COSMO model instance is required to avoid interpolation errors. The grid distance of the intermediate COSMO model is $0.36^{\circ}$ $(\approx 40 \mathrm{~km})$. Figure 2 illustrates this for all three cases: The interior, darker grey area indicates the COSMO model domain (Fig. 2a for 1st and 2nd case, Fig. 2b for 3rd case), where the off-line and on-line simulations are compared. The lighter grey area corresponds to the larger domain of the intermediate COSMO instance. This results in a $\operatorname{MECO}(2)$ setup with three model instances: $\mathrm{EMAC} \rightarrow \operatorname{COSMO}(40 \mathrm{~km}) / \mathrm{MESSy} \rightarrow \operatorname{COSMO}(7 / 14 \mathrm{~km}) /$ MESSy.

Figure $1 \mathrm{~b}$ schematically illustrates the setup of the MECO(2) system: Boundary data for both COSMO/MESSy instances are provided at every EMAC time step, i.e. every six minutes, even though the intermediate COSMO instance uses a time step of $120 \mathrm{~s}$ and the target COSMO instance a time step of $40 \mathrm{~s}$. The higher frequency of boundary data provision compared to the off-line simulations (Fig. 1a) is required, since with the on-line coupling the boundary data is no longer interpolated in time, but changes instantaneously to new values at each coupling time step (for more details about the technical realisation of the on-line coupling see Kerkweg and Jöckel, 2012b). As this study considers specific meteorological situations, the climate model EMAC has been nudged to the "observed" meteorology, i.e. to the same ECMWF analysis data set that is used for the generation of the initial and boundary data of the off-line simulations. We applied a weak nudging of four prognostic model variables: temperature, divergence, vorticity and the logarithm of surface pressure (described in Jöckel et al., 2006). The nudging is only applied on the synoptical scale in the free troposphere, allowing the EMAC model to develop to a certain degree "its own dynamics".

As shown in Fig. 1a, for the off-line simulations, ECMWF analysis data are directly transformed and interpolated to the COSMO grid using the pre-processing tool INT2LM. In case of a $\mathrm{MECO}(2)$ simulation, EMAC is initialised by ECMWF analysis data interpolated (in an off-line pre-processing step) to the EMAC grid by the program INTERA. During the initialisation phase the initial fields of EMAC are interpolated to the intermediate COSMO model grid using INT2COSMO (i.e. the "on-line version" of INT2LM). Finally, during the initial phase of the intermediate COSMO simulation, its initial fields are again interpolated by INT2COSMO to the target COSMO model grid. Thus, while the off-line COSMO simulation gets its initial fields by one interpolation, the initial fields of the on-line COSMO simulation are the result of three interpolation steps, where the first interpolation coarsens the data fields (onto the EMAC grid), before it is interpolated twice to a finer grid. Thus we expect small differences due to the various interpolation steps in the initial conditions of the off-line and on-line COSMO simulations. Nevertheless, the basis for both simulations are ECMWF analyses and the resulting initial fields are very similar.

\section{Case studies}

Figure 2a shows the regions of both COSMO instances in the $\operatorname{MECO}(2)$ setup, which are used for the first two case studies. The smaller COSMO has a grid point distance of $0.0625^{\circ}$ $(\approx 7 \mathrm{~km})$, the coarser COSMO simulations with a grid point distance of $0.36^{\circ}(\approx 40 \mathrm{~km})$. Figure $2 \mathrm{a}$ also shows the coarser grid of EMAC $(\approx 90 \mathrm{~km})$.

\subsection{Case 1: cold-frontal passage}

In the first case study the cold-frontal passage of a lowpressure system named "Judy" and the associated precipitation over Germany is analysed.

At the beginning of 26 March 2010 "Judy" developed as a weak depression along the occluding front of a complex low-pressure system located over Great Britain and moved towards northeastern Germany later during the day. Warm subtropical air transported from southern regions ahead of the surface cold front and cold moist air advected equatorward behind the front led to a large horizontal temperature contrast up to $15^{\circ} \mathrm{C}$ over Germany. Strong wind gusts and intense precipitation characterised this frontal passage over Germany. Two different start times (00:00 UTC, 24 and 26 March) are used to investigate the passage across Germany of this marked cold front. The different lead times of these simulations relative to the frontal passage (two days compared to a few hours) are important for the performance of the simulations, which both end at 00:00 UTC, 28 March. In the following, the COSMO simulations are labelled as described in Sect. 3. Figure 4 compares the temporal development of typical meteorological parameters averaged in the area of Germany. Only some slight deviations between model simulations and verifying ECMWF analyses are apparent, concerning mainly the maximum and minimum values. While specific humidity (Fig. 4b) is better represented by the off-line simulations at the beginning of the simulations, sea level pressure (SLP, Fig. 4d) and geopotential height (Fig. 4c) are better captured at the end of the simulations. On-line simulations yield better results for the overall temperature development (Fig. 4a) and for SLP at the beginning of the simulation.

As described in Sect. 2, initial fields of all simulations are calculated from ECMWF analyses. After the initialisation, the off-line simulations obtain information from ECMWF analyses directly at the boundaries. In contrast, the boundary data for the $\operatorname{MECO}(2)$ system is provided by the global driving model EMAC, whose simulations are nudged by 

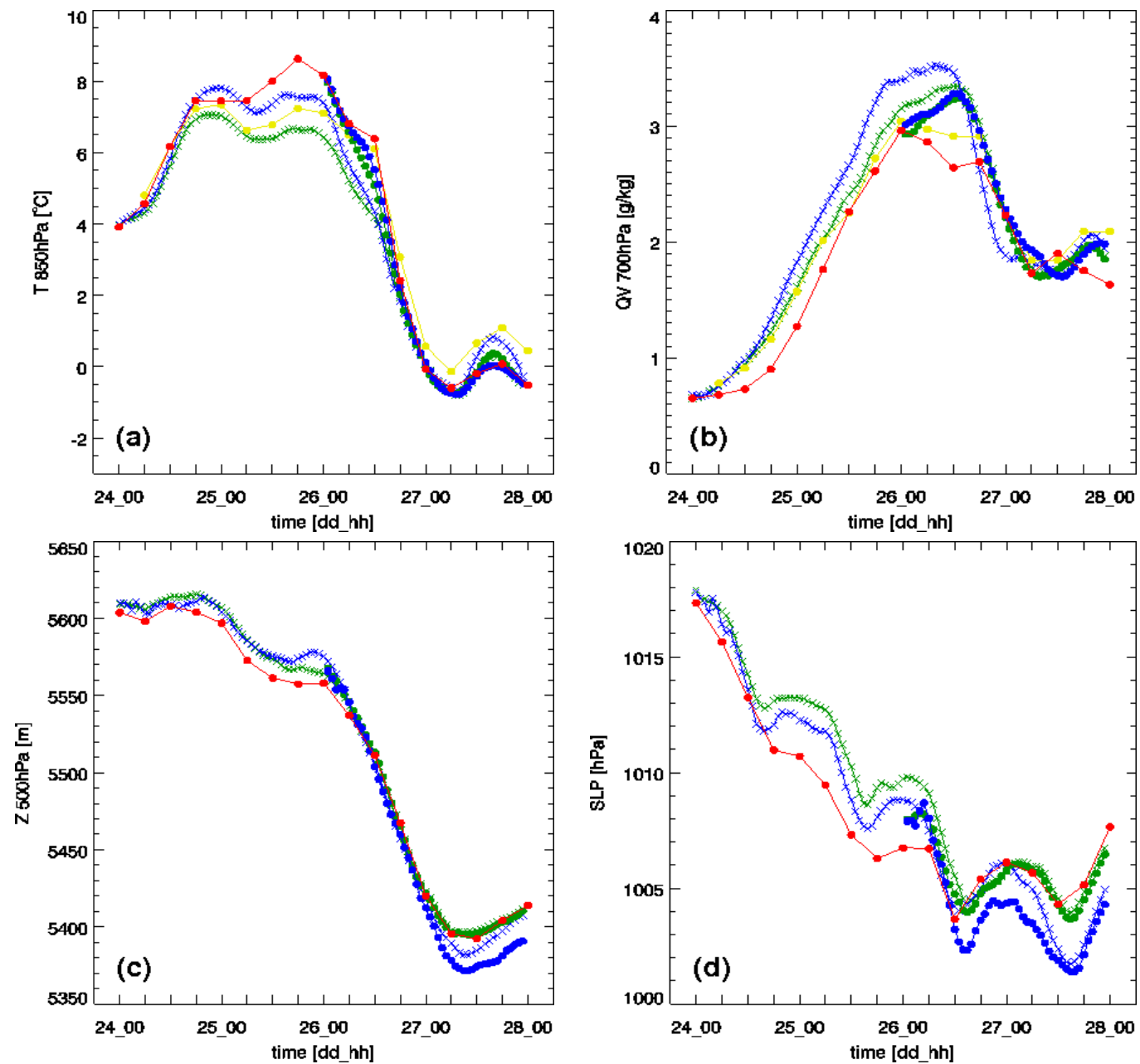

- ECMWF

- EMAC

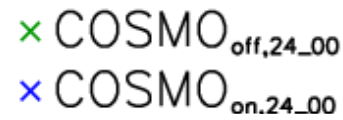

- $\mathrm{COSMO}_{\text {off,26_oo }}$

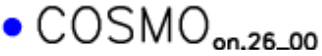

Fig. 4. Time series of typical meteorological parameters averaged in the area of Germany for the frontal case from 00:00 UTC, 24 March to 00:00 UTC, 28 March 2010. Shown are (a) temperature $\left(T\right.$, in $\left.{ }^{\circ} \mathrm{C}\right)$ at $850 \mathrm{hPa}$, (b) specific humidity $\left(\mathrm{QV}\right.$, in $\left.\mathrm{g} \mathrm{kg}^{-1}\right)$ at $700 \mathrm{hPa}$, (c) geopotential height $(Z$, in $\mathrm{m}$ ) at $500 \mathrm{hPa}$ and (c) sea level pressure (SLP, in hPa). Because the output of $Z$ and SLP is not available for EMAC, time series of these variables are not shown for EMAC in panels (c) and (d).

ECMWF analyses. In spite of this important difference, simulations of the two types develop in a very similar way. The essential development of the different parameters, e.g. a strong temperature decrease accompanying the frontal passage (Fig. 4a), is captured by all simulations. Keeping in mind that these time series are averaged over a large area (Germany), no essential differences appear for the different lead times of the simulations. In summary, regionally averaged values of the on- and off-line simulations evolve similarly and compare favourably with the reference analyses.

To get an impression of the spatial representation of the cold front, Fig. 5 shows low-tropospheric temperature and wind fields in Germany and the neighboring countries. The large temperature gradient mentioned above is obvious in all simulations as well as the strong southerly winds. But there are also significant differences, especially for the COSMO simulations with longer lead times: the temperature gradient in the simulation $\mathrm{COSMO}_{\text {off,24_00 }}$ is clearly underestimated compared to the ECMWF analyses, whereas in $\mathrm{COSMO}_{\text {on,24_00 }}$ the position of the front is too far to the east. Although the fields in $\mathrm{EMAC}_{24}$ _00 look almost the same as the ones in $\mathrm{EMAC}_{26 \_00}$ (not shown), $\mathrm{COSMO}_{\text {on,26_00 }}$ performs much better than $\mathrm{COSMO}_{\text {on,24_00. The simulations }}$ with longer lead time have been initialised $48 \mathrm{~h}$ earlier with slightly different initial fields (described in Sect. 2). After their initialisation, COSMO models are able to develop their own dynamics and the resulting fields increasingly differ with increasing runtime. 

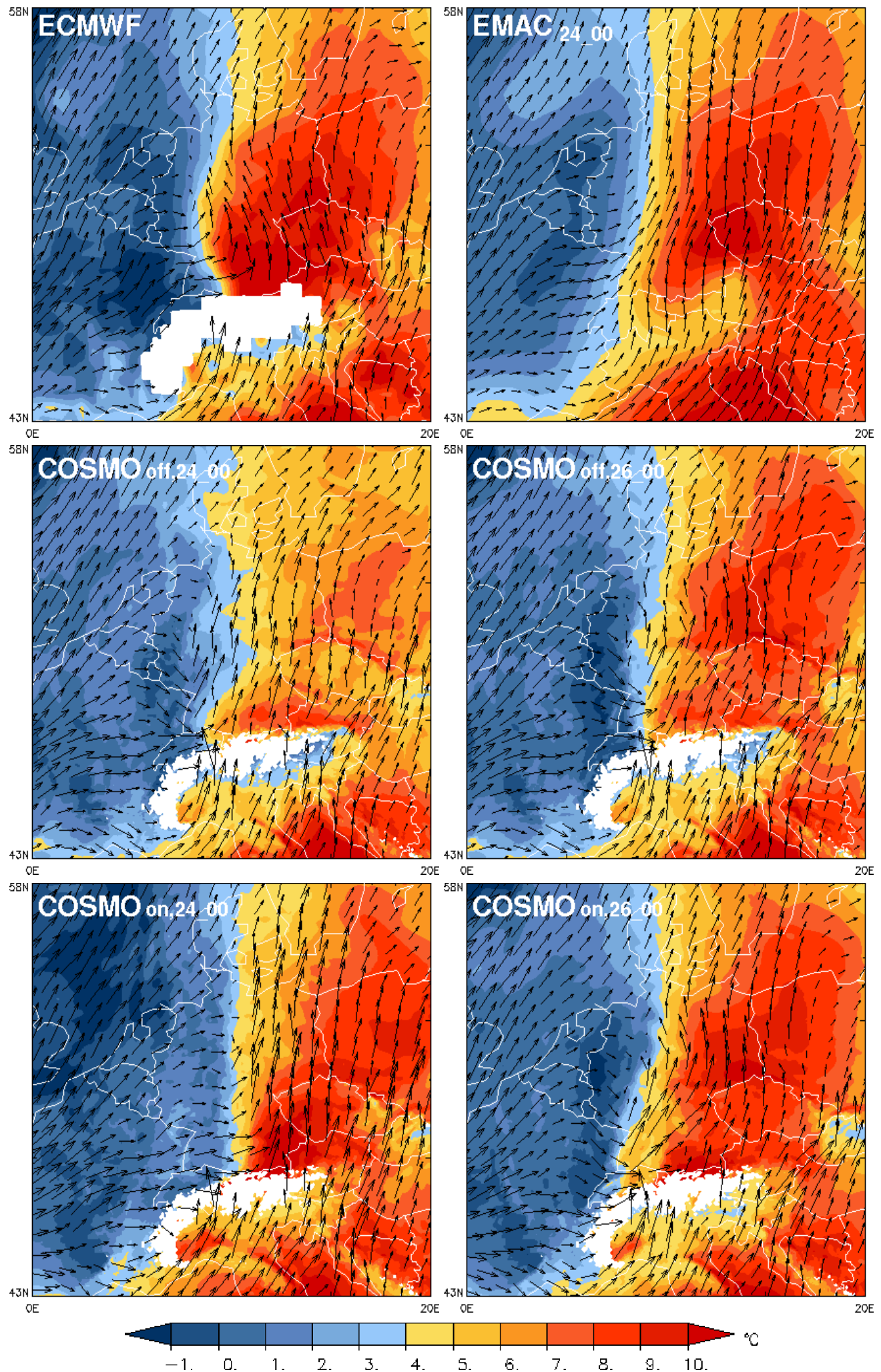

Fig. 5. Temperature (colours, in ${ }^{\circ} \mathrm{C}$ ) and horizontal wind vectors at $850 \mathrm{hPa}$ at 12:00 UTC, 26 March 2010 for different model simulations and ECMWF analyses (top left panel). 


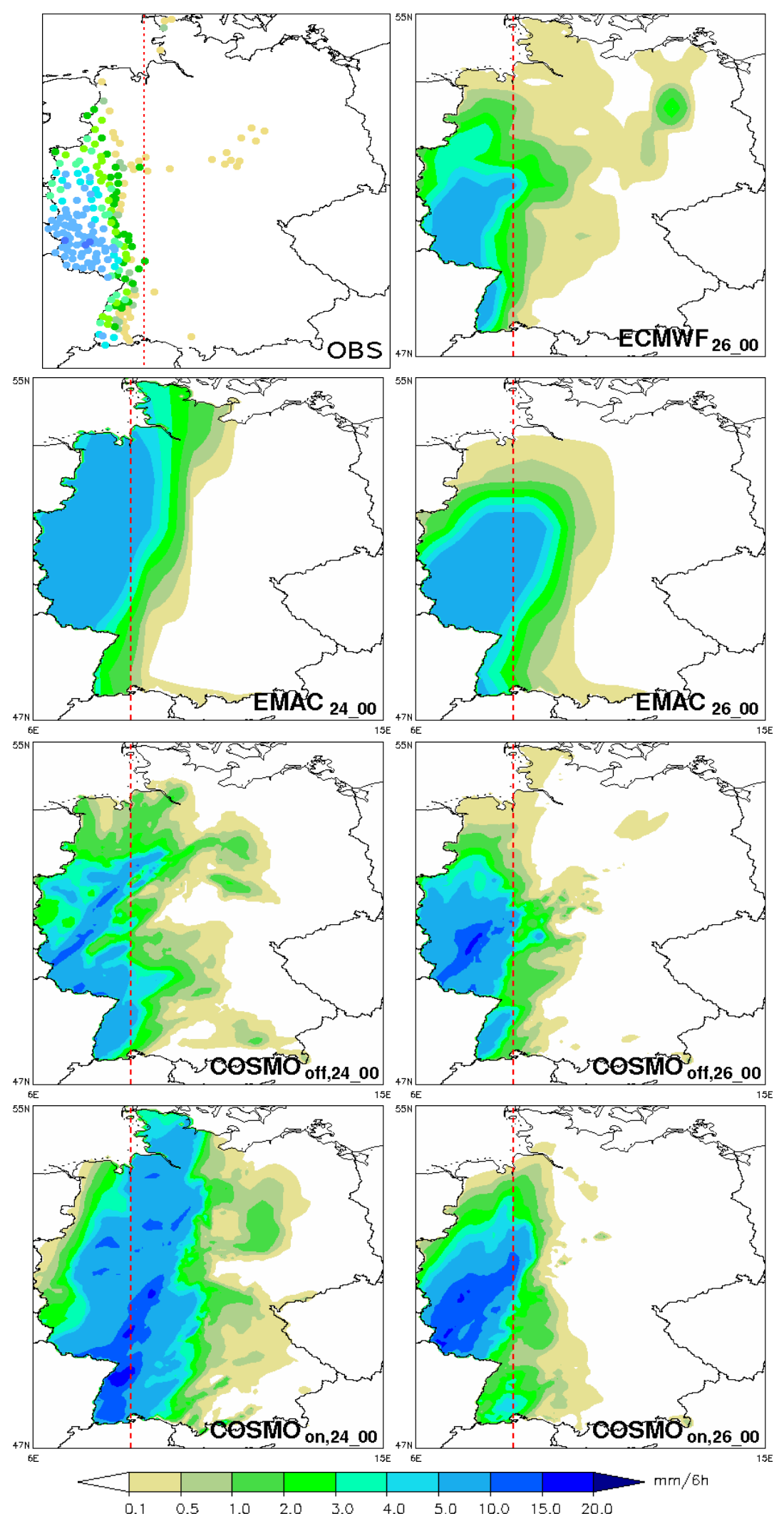

Fig. 6. 6h-accumulated precipitation for 06:00-12:00 UTC, 26 March 2010 for different simulations and rain gauge observations (top left panel). The red dashed line enables a better comparison between the location of the precipitation fields. 


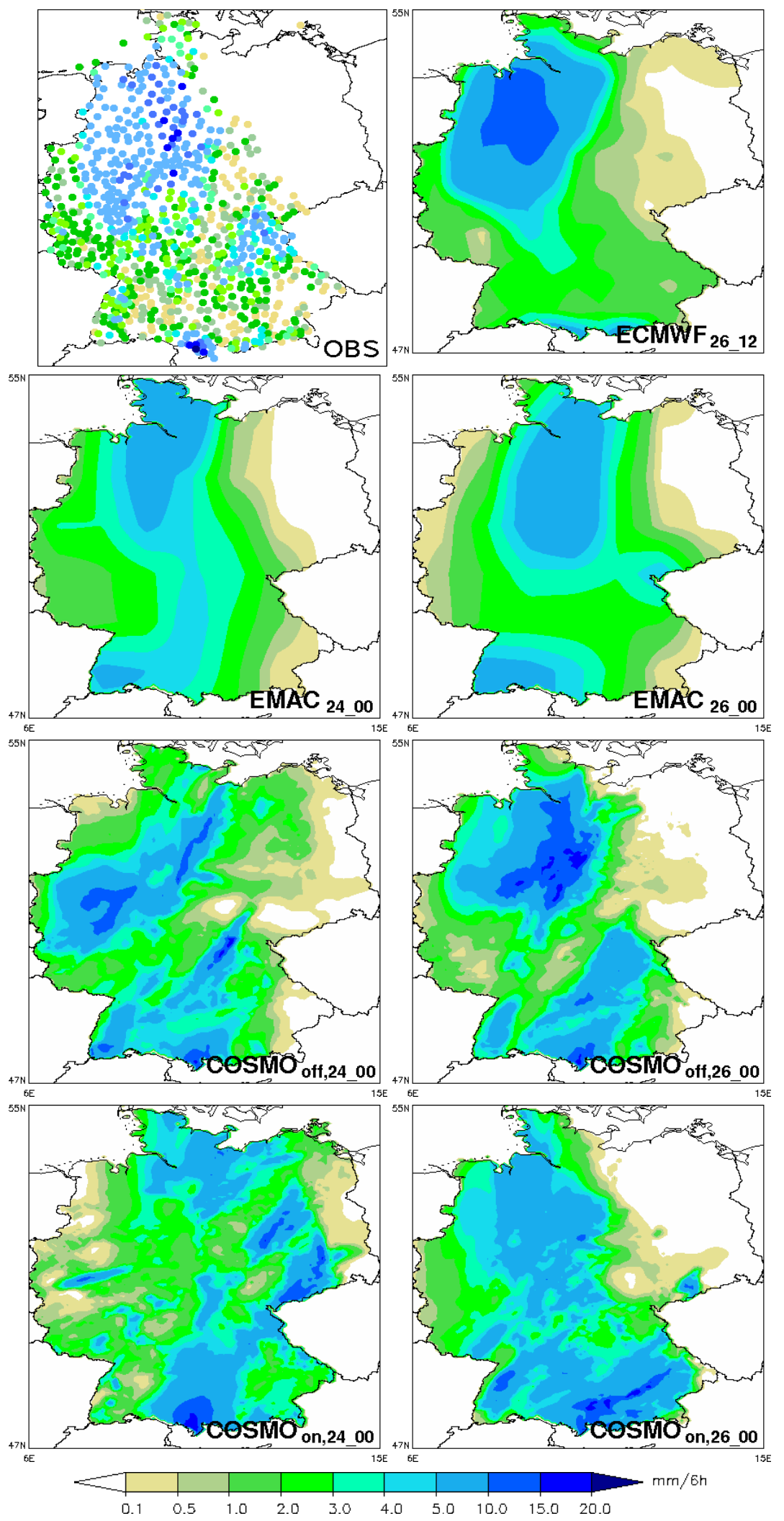

Fig. 7. 6h-accumulated precipitation for 12:00-18:00 UTC, 26 March 2010 for different simulations and rain gauge observations (top left panel). 
Comparing the 6-hourly accumulated simulated precipitation between 06:00 and 12:00 UTC (Fig. 6) leads to similar results: the frontal rainfall and its propagation over Germany is well simulated in all cases. In general, intensity and location of the frontal band of precipitation agree with the observational data of the rain gauge stations for all COSMO simulations apart from a few slight deviations. The EMAC simulation with longer lead time $\left(\mathrm{EMAC}_{24} \_00\right)$ shows the most obvious deviation in Fig. 6, as the precipitation field reaches too far to the north. Due to the performance of its driving model,

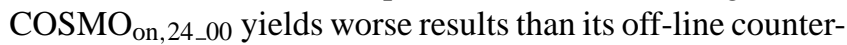
part $\mathrm{COSMO}_{\text {off,24_00 }}$. For the simulations with shorter lead times, results of $\mathrm{COSMO}_{\text {on, 26_00 }}$ are as close to the obser-

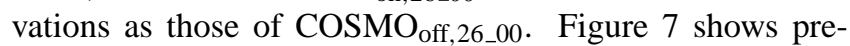
cipitation accumulated between 12:00 and 18:00 UTC. During this period the front propagates across Germany. The observations show three precipitation maxima: the largest one in the north east, one to the north of the Alps and one near the Czech border (Fichtelgebirge). The largest maximum is well reproduced in the simulations with shorter lead time. The third maximum is missing in the ECMWF shortrange forecast, it is too far in the east in on-line and too large in off-line simulations, whereas the southern field is much too strong in all COSMO simulations. Although the front in $\mathrm{EMAC}_{24 \_00}$ is located nearly at the same place as in $\mathrm{EMAC}_{26 \_00}, \mathrm{COSMO}_{\text {on,26_00 }}$ produces much better re-

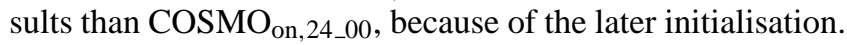
Again, all simulations with longer lead times show stronger deviations, which is understandable, because these simulations could develop their own dynamics during sixty hours.

Summarising this first case study, $\operatorname{MECO}(2)$ is able to simulate a frontal passage accompanied by large scale precipitation. Nevertheless, simulations with a shorter lead time perform better. Comparing the off- and on-line simulations for different parameters, differences between the simulations occur in the range of the spread, as a usual COSMO ensemble forecast would have.

\subsection{Case 2: intense linearly organised convection during the COPS campaign}

In a second case study the performance of $\operatorname{MECO}(2)$ in simulating an event of convective summertime precipitation in Central Europe is analysed. Therefore a frontal passage dominated by convective processes on 20 July 2007 was selected. The event occurred during the COPS field experiment (Convective and Orographically induced Precipitation Study, Wulfmeyer et al., 2011) and is referred to as the intense observations period IOP-9c. As described in Kottmeier et al. (2008), a mesoscale convective system over eastern France was mainly responsible for initiating convection in this case. Its cold front formed and propagated quickly north-eastward during the morning of 20 July. Ahead of the front, thermally driven circulations caused the formation of a convergence line, which triggered several new convective cells. This case

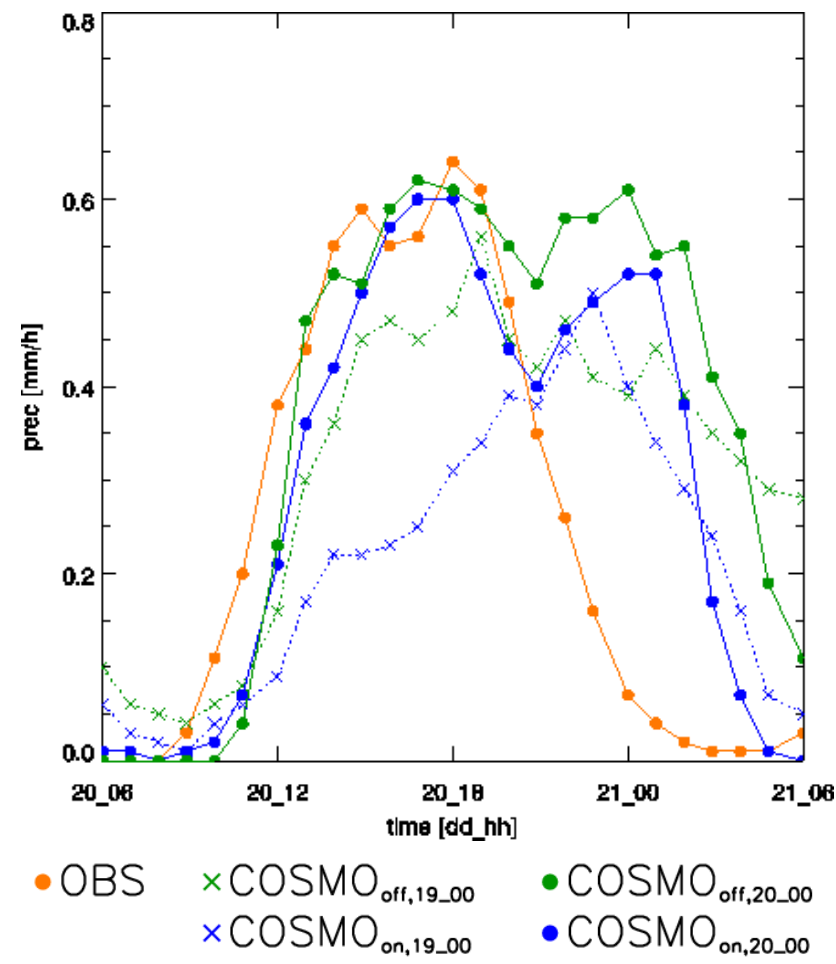

Fig. 8. Diurnal cycle of averaged precipitation in the area of Germany from 06:00 UTC, 20 July to 06:00 UTC, 21 July 2007, as observed and simulated by different COSMO simulations.

has also been investigated using different observational data to identify the processes responsible for initiating the convection (Corsmeier et al., 2011). Schwitalla et al. (2011) simulated this case using the WRF model ${ }^{3}$.

As in the previous section, off- and on-line simulations starting at two different times are compared in this case study. The simulations with longer lead times are started at 00:00 UTC, 19 July, the ones with shorter lead time at 00:00 UTC, 20 July. The end time of all simulations is 12:00 UTC, 21 July. The COSMO region and resolution is the same as in Sect. 5.1.

Figure 8 shows the diurnal cycle of precipitation associated with the passage of this front, averaged over Germany. Obviously, the simulations with the longer lead times, $\mathrm{COSMO}_{\text {on,19_00 }}$ and $\mathrm{COSMO}_{\text {off, } 19 \_00}$, have difficulties to produce the right amount of precipitation. While $\mathrm{COSMO}_{\text {on,19_00 }}$ underestimates precipitation at the beginning of the event, $\mathrm{COSMO}_{\text {off, } 19 \_00}$ produces too much rainfall at the end. Starting the simulations $24 \mathrm{~h}$ later leads to a considerable improvement. On- and off-line simulations are very similar at the beginning of the simulation. Compared to the distribution of the observed precipitation, they reach the first maximum with correct intensity, but approximately three hours later than observed. Figure 9 shows the

\footnotetext{
${ }^{3}$ http://www.wrf-model.org/index.php
} 

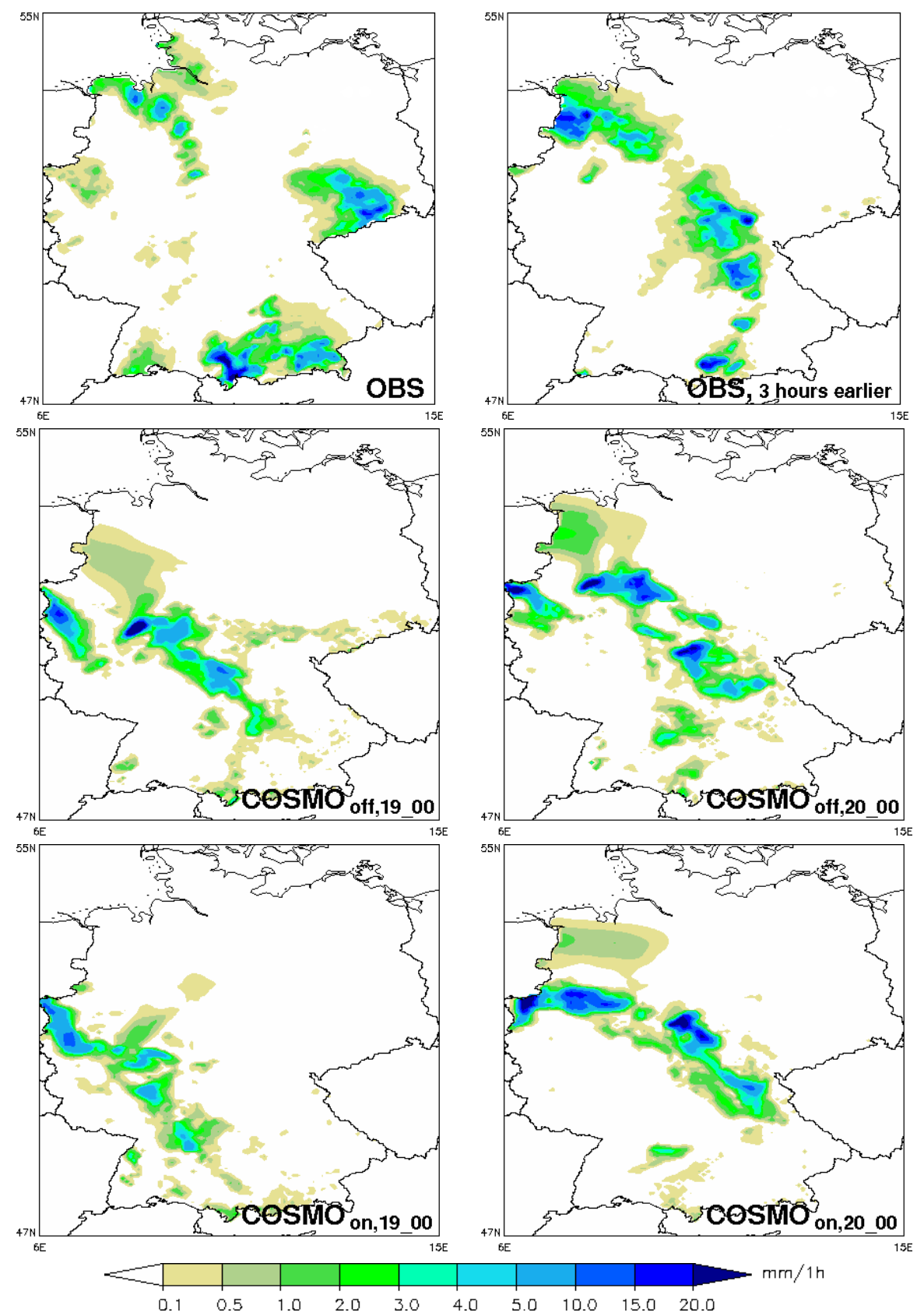

Fig. 9. 1 h-accumulated precipitation for 17:00-18:00 UTC, 20 July 2007 for different simulations and an observational data set (top left panel). In addition, the top right panel shows the observed 1h-accumulated precipitation for 14:00-15:00 UTC.

structure of the precipitation field and confirms the time offset of approximately $3 \mathrm{~h}$. Apart from the convective structures in the foothills of the Alps, COSMO simulations with shorter lead times produce the precipitation associated with the front nearly at the same place as observed three hours earlier. Clearly, on the small scale there are also some deviations between the short-range COSMO simulations and the observations, especially considering the location and strength of the precipitation maxima along the front.
While according to Fig. 8 the observed precipitation reveals a second maximum about four hours later, the distance to the second maximum in both COSMO simulations is considerably longer, approximately seven hours. Regarding the spatial distribution of the precipitation in Fig. 10, this second maximum can be dedicated to convective precipitation in the area of the foothills of the Alps, which is not associated with the frontal passage. As all COSMO models simulate this convection later than observed, the second maximum in 

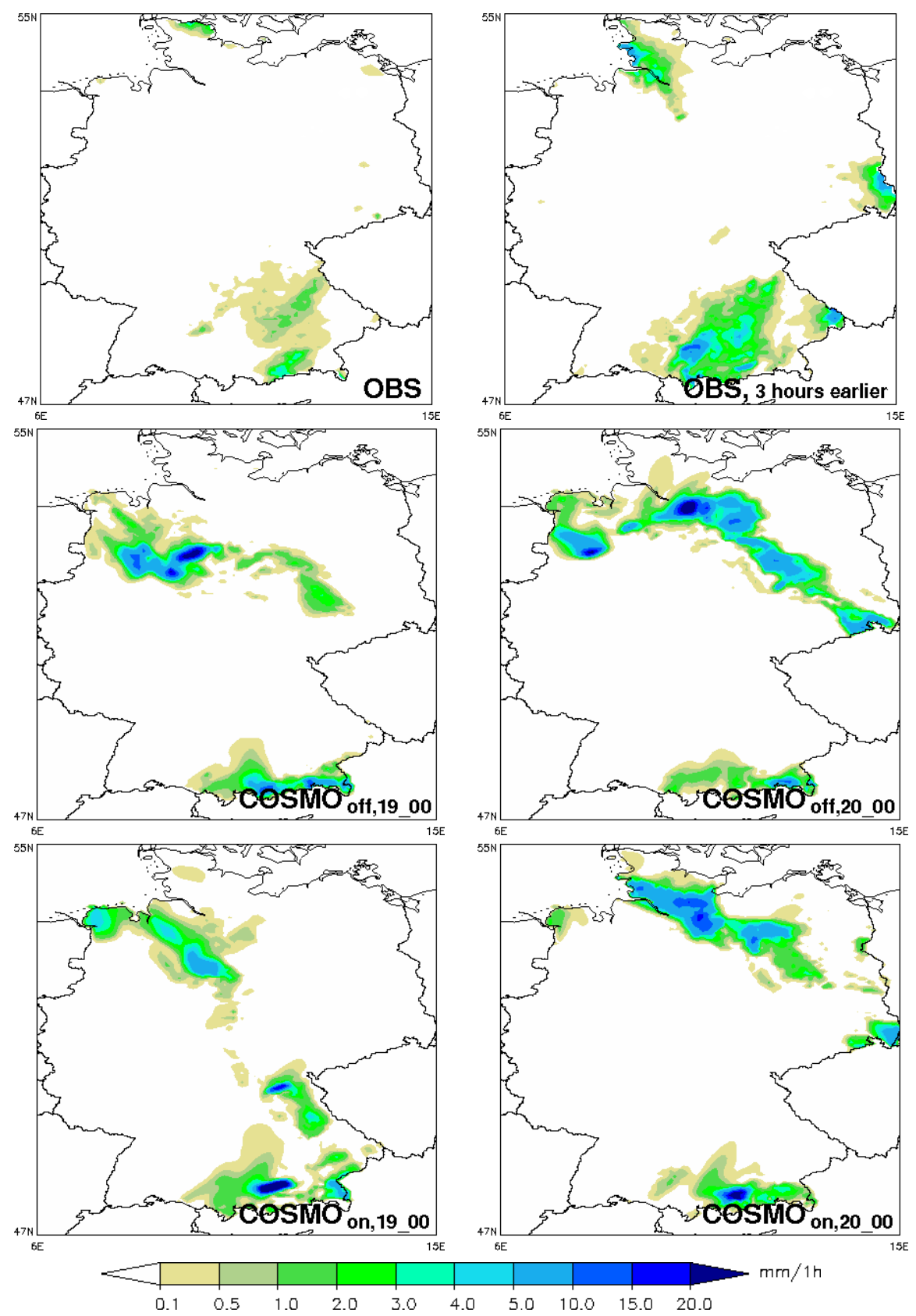

Fig. 10. 1h-accumulated precipitation for 23:00 UTC, 20 July to 00:00 UTC, 21 July 2007 for different simulations and an observational data set (top left panel). In addition, the top right panel shows the observed 1h-accumulated precipitation for 20:00-21:00 UTC, 20 July.

Fig. 8 appears delayed and not as strong as observed, because the frontal convection already starts decaying.

Although for numerical weather prediction models convection is one of the most difficult processes to simulate accurately, on- and off-line COSMO simulations produce the frontal convection reasonably well, with a slight time shift but approximately at the right place. Keeping in mind that the aim of this study is to test the $\operatorname{MECO}(2)$ system concerning its meteorological performance, it is also very important to realise that the on-line simulations perform also for this case study as good as the off-line simulations.

\subsection{Case 3: development of winterstorm Kyrill}

In the third case, the accuracy of the synoptic evolution of the winterstorm "Kyrill" is investigated in the various model simulations. As shown by Fink et al. (2009), the development of this cyclone can be separated in two stages. The 

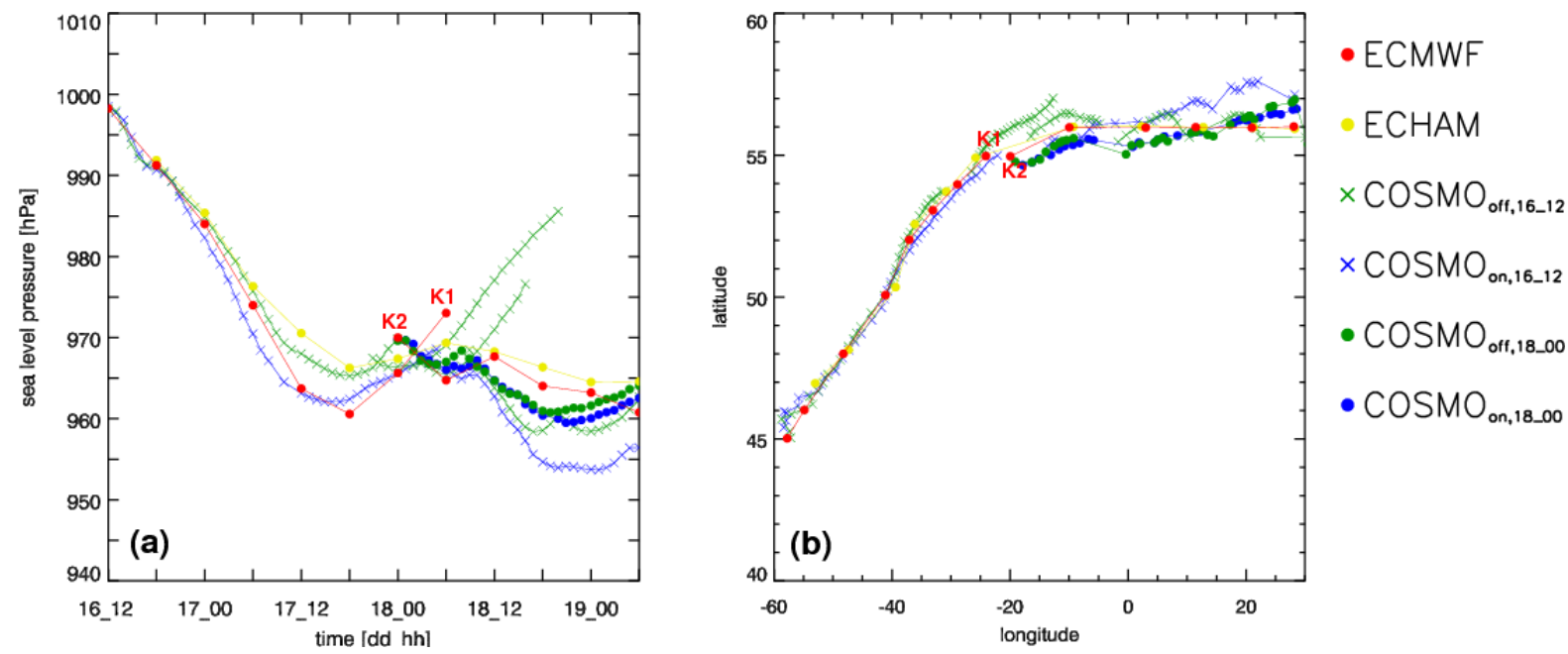

Fig. 11. (a) Temporal development of minimum sea level pressure (in hPa, from 12:00 UTC, 16 January to 06:00 UTC, 19 January), and (b) the track of winterstorm "Kyrill" to the east of $60^{\circ} \mathrm{W}$ for different model simulations and ECMWF analyses. Label K1 denotes the end of the original cyclone, label $\mathrm{K} 2$ denotes the beginning of the second depression.

original "Kyrill" cyclone, hereafter named K1, formed over northeastern Arkansas (USA) during 14 January, thus about four days before "Kyrill" caused strong storm damages in Europe between 17 and 19 January 2007. Driven by the upper-level flow, K1 propagates north-eastward to the western North Atlantic, where it experiences a rapid intensification. According to ECMWF analyses (Fig. 11), there is a remarkable pressure decrease in the centre of the cyclone by $35 \mathrm{hPa}$ between 12:00 UTC, 16 January $(998 \mathrm{hPa})$ and 12:00 UTC, 17 January (963 hPa). At 00:00 UTC, 18 January, just at the time when the propagation of $\mathrm{K} 1$ over the North Atlantic comes to a halt, occludes, and starts to decay, a second depression, referred to as $\mathrm{K} 2$, forms at the occlusion point of K1. In the following, K2 experiences a further intensification again triggered mainly by upper level processes (described in Fink et al., 2009), which led to an even deeper core pressure ( $961 \mathrm{hPa}$ according to ECMWF analyses) compared to its parent cyclone K1. Afterwards, K2 keeps its low pressure and associated intense circulation while moving across Central and Eastern Europe, causing strong storm damages. As shown by Fink et al. (2009), damage occurred in an exceptionally large area (compared to other damaging European winterstorms). In the following, we focus on the representation of the development of "Kyrill" over the North Atlantic in the model simulations, in particular on the track and the development of minimum sea level pressure (SLP) for $\mathrm{K} 1$ and $\mathrm{K} 2$.

Because of the fairly large domain required to capture the evolution of this storm, a coarser grid point distance of $0.125^{\circ}(\approx 14 \mathrm{~km})$ is selected for the inner COSMO region (Fig. 2b), compared to the first two case studies. As before, the coarser COSMO model uses a grid point distance of $0.36^{\circ}(\approx 40 \mathrm{~km})$, and the driving model EMAC is used in the T106L31 setup. The simulations with longer lead times are started on 12:00 UTC, 16 January, the ones with shorter lead time at 00:00 UTC, 18 January. All simulations end at 12:00 UTC, 19 January.

Using the tracking algorithm of Wernli and Schwierz (2006), the track of "Kyrill" and the time evolution of the cyclone's minimum SLP are determined in the analyses and model simulations, as shown in Fig. 11. First the COSMO simulations starting at 12:00 UTC, 16 January (marked with crosses in Fig. 11) are compared with ECMWF analysis data. The decrease of the minimum SLP associated with $\mathrm{K} 1$ corresponds more favourably to the analysis data in the simulation $\mathrm{COSMO}_{\text {on, } 16-12}$ than in $\mathrm{COSMO}_{\text {off, } 16 \_12}$. In $\mathrm{COSMO}_{\text {off, } 16-12}$, K1 reaches a minimum SLP that is $5 \mathrm{hPa}$ too high compared to the analyses. The tracks of $\mathrm{K} 1$ are nearly identical for all simulations. For K2 the performance of the two simulations is reversed and the simulation $\mathrm{COSMO}_{\text {off, } 16 \_12}$ has a deviation of up to $7 \mathrm{hPa}$. While it is possible to follow the track of $\mathrm{K} 2$ in the simulation $\mathrm{COSMO}_{\text {on,16_12, }}$, there are difficulties in following $\mathrm{K} 2$ in

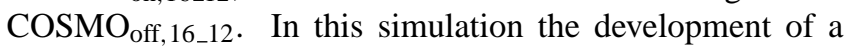
new depression near the parent cyclone, associated with a new minimum in SLP, occurs three times instead of once. These additional depressions are also striking in Fig. 11a.

As in the previous case studies, there are no remarkable differences concerning the COSMO simulations with shorter lead time. Starting at the time when K2 begins to develop, the temporal evolution of central SLP and the track are very similar in $\mathrm{COSMO}_{\text {on, } 18 \_00}$ and $\mathrm{COSMO}_{\text {off, } 18 \_00}$. As mentioned in Fink et al. (2009), the estimates of minimum SLP along the track of "Kyrill" are around $960 \mathrm{hPa}$ and the offand on-line COSMO simulations are both close to this value. 

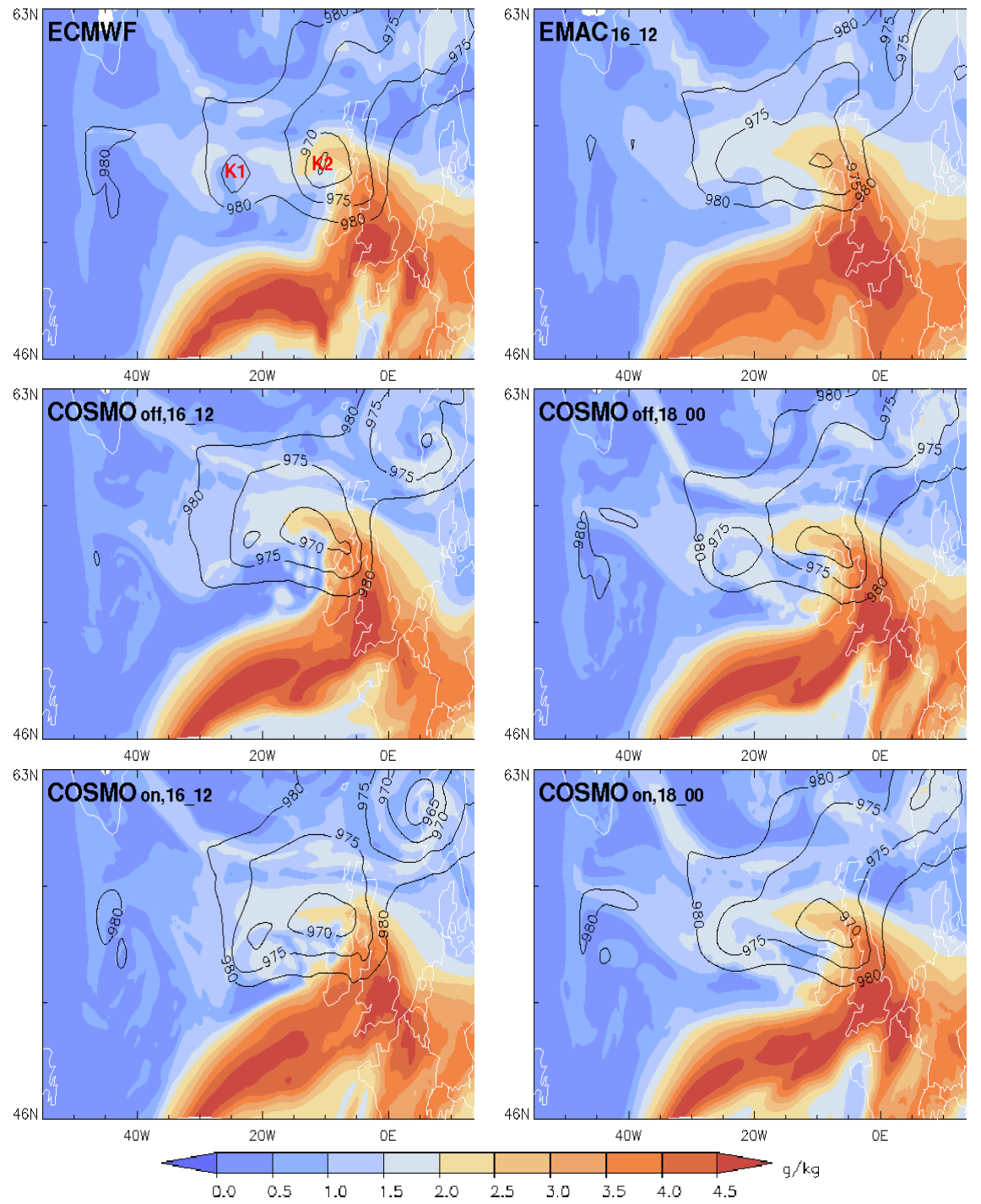

Fig. 12. Specific humidity at $700 \mathrm{hPa}$ (colours, in $\left.\mathrm{g} \mathrm{kg}^{-1}\right)$, contours of SLP $(965,970,975$, and $980 \mathrm{hPa})$ in the environment of "Kyrill" at 06:00 UTC, 18 January for the ECMWF analysis (top left), the EMAC simulations (top right), several COSMO simulations. Both centres of the depression $(\mathrm{K} 1, \mathrm{~K} 2)$ are marked in the top-left panel.

Figure 12 shows the field of specific humidity at $700 \mathrm{hPa}$ and contours of SLP at 06:00 UTC, 18 January 2007. Six hours after the genesis of the second depression, all simulations capture the dipolar structure of "Kyrill" with the two local SLP minima K1 and K2. The characteristic distribution of specific humidity of this cyclone, including the marked gradients across the surface fronts, is well captured even by the simulations with longer lead times.

Also for this case study it can be concluded, that the $\operatorname{MECO}(2)$-system is able to simulate the dynamical evolution of an intense extratropical cyclone like "Kyrill". The development of the cyclone track, minimum SLP, the humidity field, and further parameters (not shown) are captured well (in parts even better) compared to off-line COSMO simulations.

\section{Remarks about the coupling strategy}

The case studies presented in Sects. 5.1 to 5.3 provide evidence that the $\operatorname{MECO}(2)$ system is applicable to different meteorological situations. For all these studies, the COSMO instances and its driving model EMAC have been started at the same time. In this section these simulations are compared to simulations, in which EMAC starts earlier than COSMO. In this case, hereafter called "restart simulation"

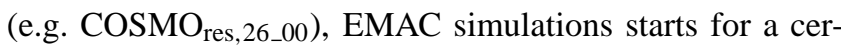
tain time before the COSMO simulations (Fig. 3). The initial fields for the COSMO simulation are calculated from the actual EMAC simulation, which is nudged with ECMWF analysis data. For a better comparison, the EMAC simulation starts at the same time as the simulation with longer lead time 

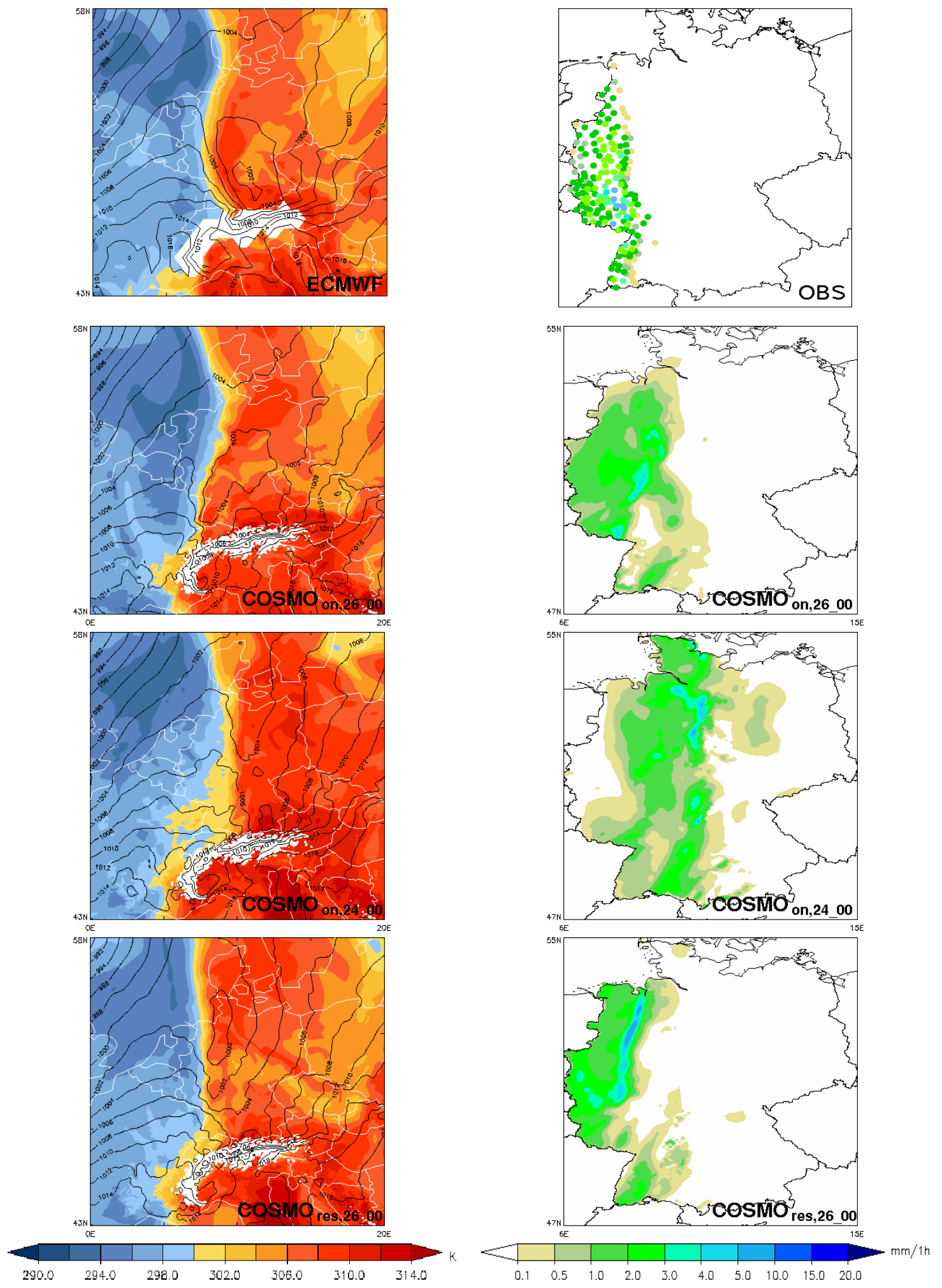

Fig. 13. Left: equivalent potential temperature $\left(\Theta_{\mathrm{e}}\right)$ at $850 \mathrm{hPa}$ (colours, in $\mathrm{K}$ ) and contours of SLP (in hPa) at 12:00 UTC, 26 March 2010. Right: 1h-accumulated precipitation for 11:00-12:00 UTC, 26 March 2010 (in mm). 

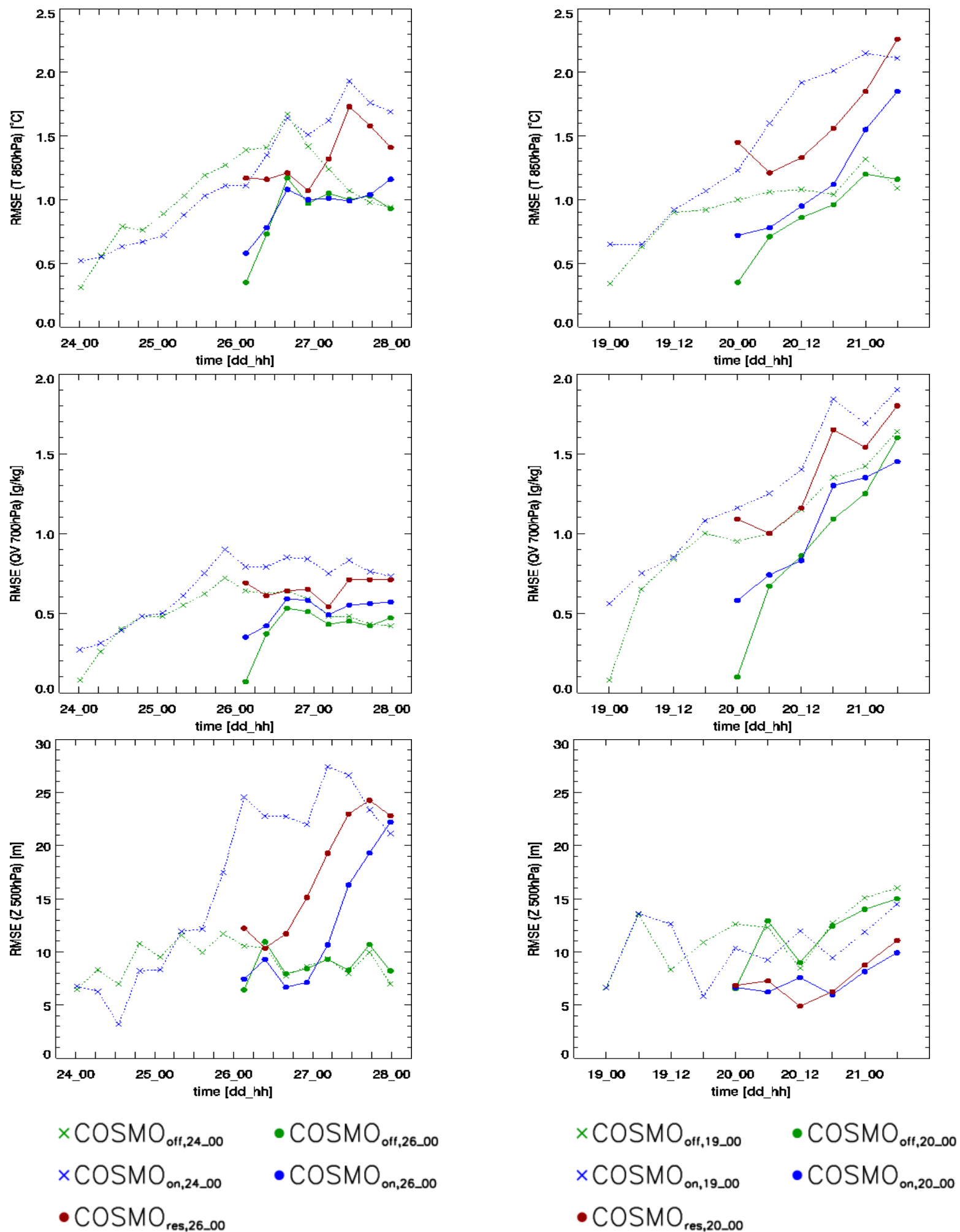

Fig. 14. Time series of the RMSE for two case studies: cold-frontal passage in March 2010 (left, Sect. 5.1) and convective front in July 2007 (right, Sect. 5.2). Top panels show RMSE of temperature at $850 \mathrm{hPa}$ (in ${ }^{\circ} \mathrm{C}$ ), middle panels RMSE of specific humidity at $700 \mathrm{hPa}$ (in $\mathrm{g} \mathrm{kg}^{-1}$ ) and bottom panels RMSE of geopotential height at $500 \mathrm{hPa}$ (in m). 
(e.g. as $\mathrm{COSMO}_{\text {on,24_00 }}$ for the frontal case), whereas the COSMO simulations start, when the simulation with shorter lead time (e.g. $\mathrm{COSMO}_{\text {on,26_00 }}$ ) were initialised.

As an example, Fig. 13 shows the resulting fields of equivalent potential temperature, SLP and precipitation for the frontal case at 12:00 UTC, 26 March 2010 (Sect. 5.1). The restart simulation $\mathrm{COSMO}_{\text {res,26_00 yields better results than }}$ $\mathrm{COSMO}_{\text {on,24_00 }}$ and simulates the front in good agreement with the analyses and observations, respectively. The minimum of SLP and the maximum of precipitation are simulated slightly too far in the north. These aspects are captured best in the simulation $\mathrm{COSMO}_{\mathrm{on}, 26 \_00}$ although in this simulation the front has already propagated too far to the east. Because both simulations differ from the reference, it is difficult to decide whether $\mathrm{COSMO}_{\text {on,26_00 }}$ or $\mathrm{COSMO}_{\text {res,26_00 lead to }}$ better results. Restart simulations for additional cases (not shown) reveal qualitatively similar results. Typically, simulations with the shortest lead time and simultaneous starts of EMAC and COSMO yield the best results.

To get further insight into the performance of the different types of simulations, Fig. 14 shows time series of the gridpoint-based root-mean-square error (RMSE) for different variables and for the two frontal cases in 2010 (Sect. 5.1) and 2007 (Sect. 5.2). Results are presented for temperature at $850 \mathrm{hPa}$, specific humidity at $700 \mathrm{hPa}$, and geopotential at $500 \mathrm{hPa}$. The RMSE is calculated between the COSMO simulations and the ECMWF analyses for the complete smaller region (Fig. 2a) except for a boundary frame of 15 gridpoints. Comparing first off-line and on-line COSMO simulations, their development is very similar at the beginning. After a certain time, the RMSE of the on-line simulation rises faster, resulting in smaller errors for $\mathrm{COSMO}_{\text {off }}$ at the end of most simulations. As the comparison is made with ECMWF analyses, this outcome is not surprising: while the boundary fields of the off-line simulation are directly computed from ECMWF analyses, the on-line simulations get their boundary data from EMAC, which is only nudged by ECMWF analyses and develops partly its own dynamics. Because of the slight differences in calculating initial fields (described in Sect. 2), the RMSE is not zero at the initial time step. Comparing the RMSE of the restart simulation with the other on-line coupled simulations leads to the same results as mentioned above: in most cases, $\mathrm{COSMO}_{\text {res }}$ simulations yield a lower RMSE than the simulation with longer lead

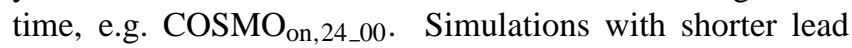
time (e.g. $\mathrm{COSMO}_{\text {on,26_00 }}$ ), however, yield the best results. Especially at the initial time step of a COSMO res $_{\text {simulation }}$ the RMSE is fairly high, sometimes even higher than in the simulations with longer lead time, because of the calculation of the initial field from EMAC. Comparing the different parameters, nearly all parameters develop similarly. The RMSE values for the frontal case are generally lower, indicating that the cold frontal passage (Fig. 14, left panel) is easier to simulate than the convective case (Fig. 14, right panel) for the COSMO model. Only the RMSE of the geopotential for the convective case deviates from this behaviour. Here $\mathrm{COSMO}_{\text {res }}$ appears to be as good as $\mathrm{COSMO}_{\text {on,20_00 }}$ and both simulations are clearly better than the off-line simulations. Note, however, that all simulations lead to very good results for the geopotential in this case, as RMSE values are very small.

In summary, the experiments indicate that in order to get the best results for a certain meteorological event, the best way to handle $\operatorname{MECO}(2)$ is to start simulations of EMAC and COSMO at the same time and as closely as possible to the time of the event. If initial fields for EMAC simulations are only available a few days before the event, it is preferable to do a restart simulation than to start also COSMO with an extended lead time.

\section{Conclusions}

This third part of a series of articles on the new 1-way on-line coupled chemistry model system MECO(n) presents three case studies associated with intense surface weather conditions in order to test the model system's ability in accurately representing the meteorological flow evolution. This is a prerequisite for future application of the $\mathrm{MECO}(\mathrm{n})$ model system for chemical weather forecasts or field campaign modeling. Only for chemistry applications the entire capability of the MECO(n) system is clearly evident, as to our knowledge only this system can provide fully consistent boundary conditions for regional chemistry applications.

To assess the meteorological performance of the on-line coupling, simulations with the new system are compared with standard off-line simulations, where the boundary conditions of the regional model COSMO are calculated by temporal interpolation from 6-hourly available ECMWF analyses. In contrast, the on-line simulations obtain updated boundary data at every time step of the global model EMAC, which is nudged with the ECMWF analyses. The off-line simulations are used as a benchmark and various model validation diagnostics are applied to quantify the accuracy of the two types of simulations for the three case studies in comparison to ECMWF analyses and observed precipitation fields. For all on-line simulations a double nesting is applied, with a first coarser COSMO/MESSy instance nested within EMAC (with a grid spacing of $40 \mathrm{~km}$ ) and a second, higher-resolution COSMO instance nested within the coarser COSMO. The model validation focuses on these higherresolution COSMO simulations.

The first case is associated with the passage of an intense cold front across Germany in March 2010. All simulations, starting at 00:00 UTC, 24 March and 00:00 UTC, 26 March capture well the pronounced temperature decrease and the passage of the upper-level trough over Germany during the 26 March. The horizontal temperature contrast of the surface front is underestimated in all COSMO simulations, but slightly less so in the on-line simulations. The structure of 
the frontal precipitation is reasonably well simulated by the later simulations starting at 00:00 UTC, 26 March. Slight deviations concerning the intensity of precipitation can be observed in the on-line simulation as well as in the off-line simulation.

The second case considers an event of intense frontal convection during the COPS field experiment in July 2007. Again, simulations with different lead times are initiated at 00:00 UTC, 19 July and 00:00 UTC, 20 July. Averaged over Germany, the later simulations produce the precipitation maximum during the evening of the 20 July rather accurately, whereas the simulations with a longer lead time strongly underestimate precipitation during this day, in particular the online simulation. In terms of precipitation structure, the later simulations (off-line and on-line) both capture to a certain degree the frontal band that extended over large parts of Germany and its intense embedded maxima of convective precipitation, however, with a time shift of approximately $3 \mathrm{~h}$. It is known from model verification studies that timing errors of up to $3 \mathrm{~h}$ are common for short-range predictions with the COSMO model of summer precipitation in Germany (Zimmer and Wernli, 2011). It is important that also for this challenging type of precipitation system, the quality of the on-line simulation is comparable to the standard off-line approach.

In the third case study, simulations of the severe winter storm "Kyrill" are considered that are initiated at 00:00 UTC on 16 and 18 January 2007, respectively. For this case, a larger model domain and a coarser resolution of the second COSMO instance have been chosen, illustrating the flexibility in the setup of the MECO(n) model system. The focus of the validation is on the track, intensity, and surface structure of the storm's secondary low pressure system that led to devastating winds in Germany on 18 January. The earlier off-line simulation is not able to produce the complex evolution associated with the genesis of the secondary low over the eastern North Atlantic. All other simulations capture this development and produce rather accurate tracks of the secondary system (although by slightly overestimating the storm's intensity). The frontal structure associated with the cyclone and the prefrontal transport of humid air masses are well represented in all simulations.

In addition, for the first and second case study, sensitivity experiments are performed to assess the sensitivity of MECO(n) simulations to the coupling strategy. As illustrated in Fig. 3, simulations with a simultaneous start of all model instances (EMAC and the two COSMO/MESSy instances) at time $t_{0}$ are compared to simulations with an earlier start of the global model EMAC (at $t_{0}-\Delta t$ ) and to simulations with a simultaneous start of all instances at the earlier time, $t_{0}-\Delta t$. The simulation errors, measured in terms of the RMSE of a set of key parameters, are typically smallest for the simulations with a simultaneous start of all models at the later time $t_{0}$. The longer the lead time, the less influence has the initial condition and the more the EMAC dynamics, which is only weakly constrained on synoptical scale by the applied nudging procedure, deviates. Therefore, the strategy with starting EMAC at an earlier time than the COSMO instances at $t_{0}$ produces larger errors. However, these simulations still perform slightly better than if all instances are launched at the earlier time $t_{0}-\Delta t$ simultaneously. Because of that, the best way to handle $\operatorname{MECO}(2)$ is to start simulations of EMAC and COSMO at the same time and as closely as possible to the time of the considered event. If this is impossible, e.g. because of missing initial fields for EMAC simulations, it is preferable to do a restart simulation than to start also COSMO with an extended lead time.

The three case study experiments indicate that the newly developed model system MECO(n) is able to simulate the meteorological evolution associated with extratropical cyclones, fronts, and frontal convection with similar accuracy than the usually performed off-line COSMO simulations driven by ECMWF analysis fields. This is a key prerequisite for the future application of the MECO(n) model system for simulations of atmospheric chemistry during complex weather situations. Clearly, the small sample of cases investigated in this study does not allow to draw a statistically robust conclusion about the overall model performance - however, the detailed comparison of frontal structures, intense frontal convection, and cyclone tracks provides important insight into the model's capability in simulating these complex meteorological phenomena, which will be essential for an accurate simulation of the transport and removal of chemical species.

Acknowledgements. This work was funded by the German Science Foundation (DFG) within the project MACCHIATO (WE 2943/4-1). We are grateful for the support of our partners in MACCHIATO: Jörg Trentmann (DWD, previously Institut for Atmospheric Physics, Mainz, Germany), Jos Lelieveld (Max Planck-Institute for Chemistry, Mainz, Germany), and Andreas Bott (Meteorological Institute, University Bonn, Germany). We appreciate the provision of the rain gauge data by the DWD Hydrometeorology Department. The authors thank the "application support for high computer performance" team of the MPG computer centre Garching, in particular I. Weidl, R. Hatzky, W. Nagel and H. Lederer. Such a development project requires a lot of computing time for testing the new model. This was supported within the project CheSS by the DEISA (Distributed European Infrastructure for Supercomputer Applications) Extreme Computing Initiative (DECI), and we thank the DEISA Consortium (www.deisa.eu), co-funded through the EU FP6 project RI-031513 and the FP7 project RI-222919.

Edited by: V. Grewe 


\section{References}

Corsmeier, U., Kalthoff, N., Barthlott, C., Aoshima, F., Behrendt, A., Di Girolamo, P., Dorninger, M., Handwerker, J., Kottmeier, C., Mahlke, H., Mobbs, S. D., Norton, E. G., Wickert, J., and Wulfmeyer, V.: Processes driving deep convection over complex terrain: a multi-scale analysis of observations from COPS IOP 9c, Q. J. Roy. Meteorol. Soc., 137, 137-155, 2011.

Doms, G. and Schättler, U.: The nonhydrostatic limited-area model LM of DWD, Part 1: Scientific documentation, Deutscher Wetterdienst, Offenbach available at: www.cosmo-model.org (last access: 2 November 2011), 1999.

Fink, A. H., Brücher, T., Ermert, V., Krüger, A., and Pinto, J. G.: The European storm Kyrill in January 2007: synoptic evolution, meteorological impacts and some considerations with respect to climate change, Nat. Hazards Earth Syst. Sci., 9, 405423, doi:10.5194/nhess-9-405-2009, 2009.

Frei, C. and Schär, C.: A precipitation climatology of the Alps from high-resolution rain-gauge observations, Int. J. Climatol., 18, 873-900, 1998.

Gebhardt, C., Theis, S. E., Paulat, M., and Ben Bouallegue, Z.: Uncertainties in COSMO-DE precipitation forecasts introduced by model perturbations and variation of lateral boundaries, Atmos. Res., 100, 168-177, 2011.

Grell, G., Peckham, S., Schmitz, R., McKeen, S., Frost, G., Skamarock, W., and Eder, B.: Fully coupled "online" chemistry within the WRF model, Atmos. Environ., 39, 6957-6975, 2005.

Jöckel, P., Sander, R., Kerkweg, A., Tost, H., and Lelieveld, J.: Technical Note: The Modular Earth Submodel System (MESSy) - a new approach towards Earth System Modeling, Atmos. Chem. Phys., 5, 433-444, doi:10.5194/acp-5-433-2005, 2005.

Jöckel, P., Tost, H., Pozzer, A., Brühl, C., Buchholz, J., Ganzeveld, L., Hoor, P., Kerkweg, A., Lawrence, M. G., Sander, R., Steil, B., Stiller, G., Tanarhte, M., Taraborrelli, D., van Aardenne, J., and Lelieveld, J.: The atmospheric chemistry general circulation model ECHAM5/MESSy1: consistent simulation of ozone from the surface to the mesosphere, Atmos. Chem. Phys., 6, 50675104, doi:10.5194/acp-6-5067-2006, 2006.

Jöckel, P., Kerkweg, A., Pozzer, A., Sander, R., Tost, H., Riede, H., Baumgaertner, A., Gromov, S., and Kern, B.: Development cycle 2 of the Modular Earth Submodel System (MESSy2), Geosci. Model Dev., 3, 717-752, doi:10.5194/gmd-3-717-2010, 2010.

Kerkweg, A. and Jöckel, P.: The 1-way on-line coupled atmospheric chemistry model system MECO(n) - Part 1: Description of the limited-area atmospheric chemistry model COSMO/MESSy, Geosci. Model Dev., 5, 87-110, doi:10.5194/gmd-5-87-2012, 2012a.
Kerkweg, A. and Jöckel, P.: The 1-way on-line coupled atmospheric chemistry model system MECO(n) - Part 2: On-line coupling with the Multi-Model-Driver (MMD), Geosci. Model Dev., 5, 111-128, doi:10.5194/gmd-5-111-2012, 2012b.

Knote, C., Brunner, D., Vogel, H., Allan, J., Asmi, A., Äijälä, M., Carbone, S., van der Gon, H. D., Jimenez, J. L., Kiendler-Scharr, A., Mohr, C., Poulain, L., Prévôt, A. S. H., Swietlicki, E., and Vogel, B.: Towards an online-coupled chemistry-climate model: evaluation of COSMO-ART, Geosci. Model Dev. Discuss., 4, 1809-1874, doi:10.5194/gmdd-4-1809-2011, 2011.

Kottmeier, C., Kalthoff, N., Barthlott, C., Corsmeier, U., Van Baelen, J., Behrendt, A., Behrendt, R., Blyth, A., Coulter, R., Crewell, S., Di Girolamo, P., Dorninger, M., Flamant, C., Foken, T., Hagen, M., Hauck, C., Hoeller, H., Konow, H., Kunz, M., Mahlke, H., Mobbs, S., Richard, E., Steinacker, R., Weckwerth, T., Wieser, A., and Wulfmeyer, V.: Mechanisms initiating deep convection over complex terrain during COPS, Meteorol. Z., 17, 931-948, 2008.

Paulat, M., Frei, C., Hagen, M., and Wernli, H.: A gridded dataset of hourly precipitation in Germany: Its construction, climatology and applipication, Meteorol. Z., 17, 719-732, 2008.

Rockel, B., Will, A., and Hense, A.: The Regional Climate Model COSMO-CLM(CCLM), Meteorol. Z., 17, 347-348, 2008.

Schwitalla, T., Bauer, H.-S., Wulfmeyer, V., and Aoshima, F.: Highresolution simulation over central Europe: assimilation experiments during COPS IOP 9c, Q. J. R. Meteorol. Soc., 137, 156175,2011

Wernli, H. and Schwierz, C.: Surface cyclones in the ERA-40 dataset (1958-2001), Part I: Novel identification method and global climatology, J. Atmos. Sci., 63, 2486-2507, 2006.

Wulfmeyer, V., Behrendt, A., Kottmeier, C., Corsmeier, U., Barthlott, C., Craig, G. C., Hagen, M., Althausen, D., Aoshima, F., Arpagaus, M., Bauer, H.-S., Bennett, L., Blyth, A., Brandau, C., Champollion, C., Crewell, S., Dick, G., Di Girolamo, P., Dorninger, M., Dufournet, Y., Eigenmann, R., Engelmann, R., Flamant, C., Foken, T., Gorgas, T., Grzeschik, M., Handwerker, J., Hauck, C., Hoeller, H., Junkermann, W., Kalthoff, N., Kiemle, C., Klink, S., Koenig, M., Krauss, L., Long, C. N., Madonna, F., Mobbs, S., Neininger, B., Pal, S., Peters, G., Pigeon, G., Richard, E., Rotach, M. W., Russchenberg, H., Schwitalla, T., Smith, V., Steinacker, R., Trentmann, J., Turner, D. D., van Baelen, J., Vogt, S., Volkert, H., Weckwerth, T., Wernli, H., Wieser, A., and Wirth, M.: The Convective and Orographically-induced Precipitation Study (COPS): the scientific strategy, the field phase, and research highlights, Q. J. Roy. Meteorol. Soc., 137, 3-30, 2011.

Zimmer, M. and Wernli, H.: Verification of quantitative precipitation forecasts on short time-scales: A fuzzy approach to handle timing errors with SAL, Meteorol. Z., 20, 95-105, 2011. 